\title{
Factors Affecting Peptide Interactions with
}

\section{Surface-Bound Microgels}

Lina Nyström ${ }^{1, *}$; Randi Nordström ${ }^{l}$; Jane Bramhill ${ }^{2,+}$; Brian R. Saunders ${ }^{2}$; Rubén ÁlvarezAsencio $^{3,4}$; Mark W. Rutland ${ }^{3,5}$; Martin Malmsten ${ }^{1, *}$

1. Department of Pharmacy, Uppsala University, P.O. Box 580, SE-752 32 Uppsala, Sweden

2. School of Materials, The University of Manchester, MSS Tower, Manchester, M13 9PL, United Kingdom

3. Department of Surface and Corrosion Science, School of Chemical Science and Engineering, KTH Royal Institute of Technology, SE-100 44 Stockholm, Sweden

4. Institute for Advanced Studies, IMDEA Nanoscience, 28049 Madrid, Spain

5. SP Technical Research Institute of Sweden, SP Chemistry, Materials and Surfaces, SE-114 86 Stockholm, Sweden 
ABSTRACT: Effects of electrostatics and peptide size on peptide interactions with surfacebound microgels were investigated with ellipsometry, confocal microscopy, and atomic force microscopy (AFM). Results show that binding of cationic poly-L-lysine (pLys) to anionic, covalently immobilized, poly(ethyl acrylate-co-methacrylic acid) microgels increased with increasing peptide net charge and microgel charge density. Furthermore, peptide release was facilitated by decreasing either microgel or peptide charge density. Analogously, increasing ionic strength facilitated peptide release for short peptides. As a result of peptide binding, the surface-bound microgels displayed pronounced deswelling and increased mechanical rigidity, the latter quantified by quantitative nanomechanical mapping. While short pLys was found to penetrate the entire microgel network and to result in almost complete charge neutralization, larger peptides were partially excluded from the microgel network, forming an outer peptide layer on the microgels. As a result of this difference, microgel flattening was more influenced by the lower Mw peptide than the higher. Peptide-induced deswelling was found to be lower for higher Mw pLys, the latter effect not observed for the corresponding microgels in the dispersed state. While the effects of electrostatics on peptide loading and release were similar to those observed for dispersed microgels, there were thus considerable effects of the underlying surface on peptide-induced microgel deswelling, which need to be considered in the design of surface-bound microgels as carriers of peptide loads, e.g., in drug delivery or in functionalized biomaterials.

\section{KEYWORDS}

Microgel, Surface-bound, Peptide, Drug delivery, Confocal microscopy, AFM 


\section{INTRODUCTION}

Microgels are lightly cross-linked polymer colloids, frequently displaying dramatic swelling/deswelling transitions in response to different stimuli. Depending on functional groups incorporated within the microgel network, responsiveness can be triggered, e.g., by temperature, ionic strength, $\mathrm{pH}$, specific metabolites, or reducing conditions. ${ }^{1,2}$ Such triggered volume transitions are of interest in various applications, such as drug delivery, functional biomaterials, and biosensors. ${ }^{3-5}$ In the context of drug delivery, microgels are of particular interest as carriers for biomacromolecular drugs, such as peptides and proteins, since they offer a water-rich environment for incorporated macromolecular drugs, thus reducing detrimental conformational changes and aggregation within the delivery system. ${ }^{3}$ Furthermore, microgels offer various additional benefits as delivery systems for such drugs, including protection against enzymatic degradation and controlled or triggered release.

While there has been considerable work done on dispersed microgels as drug carriers, much less is known about surface-bound microgels as reservoirs for localized delivery, which is of considerable interest both for drug depot formulations and drug-loaded biomaterials. In a couple of rare exceptions to this, Lyon et al. reported thermally triggered release of insulin ${ }^{6}$ and doxorubicin ${ }^{7}$ from layer-by-layer deposited PNIPAM-co-AAc microgel films. The opportunity for microgels in this area are indicated also by microgel-based surface coatings having been found to display favorable biological performance on their own. For example, Bridges et al. used PNIPAM-based microgels as surface coatings in order to improve biocompatibility, thereby reducing fibrinogen adsorption as well as human monocyte/macrophage adhesion. ${ }^{8}$ Importantly, the generation of pro-inflammatory cytokines (TNF- $\alpha$, IL-1 $\beta$, MCP-1) was also reduced for microgel-coated surfaces. In a subsequent investigation, microgel coating of poly(ethylene terephtalate) (PET) was found to reduce 
chronic inflammation, and to result in thinner fibrous capsules and higher levels of macrophages compared to the uncoated control PET. ${ }^{9}$

The controlled use of microgels as delivery systems for peptide and protein drugs requires a basic understanding of the factors determining peptide/protein loading into, distribution within, and release from, microgels, and how these effects can be controlled by various design elements and external conditions. For microgel dispersions, there have been an increasing number of mechanistic studies dedicated to the effect of microgel properties, e.g., charge ${ }^{10}$ and cross-linking density ${ }^{11}$, as well as of peptide properties, such as molecular weight ${ }^{12}$, charge (distribution) $)^{10}$, secondary structure ${ }^{13}$, and hydrophobicity ${ }^{14}$, including also effects of biodegradation of both the peptide ${ }^{15}$ and microgel network ${ }^{16}$. For surface-bound microgels, on the other hand, there is very limited prior work done in this context. Hence, it remains to be clarified whether surface-bound microgels behave similarly as dispersed microgels with respect to their performance as carriers for peptide and protein drugs, or whether the presence of the surface will change the situation, e.g., through mass transfer limitations, interfacial crowding effects, or interactions between the surface and the protein/peptide.

Given the above, as well as the need of charge contrast for efficient incorporation of peptide/protein ${ }^{17}$ and our long-standing interest in cationic peptides for therapeutic purposes, notably antimicrobial, anti-inflammatory, and anti-cancer peptides ${ }^{18-20}$, the objective of the present work was to evaluate factors affecting loading and release of cationic peptides to/from immobilized anionic microgels. For this purpose, $\mathrm{pH}$-sensitive poly(EA/MAA/BDDA) (ethyl acrylate, methacrylic acid, and 1,4-butanediol diacrylate) microgels were chosen as a model platform. ${ }^{21}$ These materials display a pronounced charge titration and resulting volume transition at close to physiological pH (see Table S1 and Figure S1, Supplementary Material), 
making them an interesting choice as delivery systems for cationic peptide and protein drugs. These microgels have previously been well characterized for various applications ${ }^{22-24}$ and, importantly, the co-monomer composition can be easily varied during synthesis to alter microgel swelling properties, allowing for tunable performance of the system. ${ }^{25}$ In the present study we employed this microgel platform in combination with the model cationic peptide poly-L-lysine (pLys, $\mathrm{pI} \approx 9\left(10.5\right.$ for isolated lysine monomers $\left.\left.{ }^{12}\right)\right)$. The microgel properties and swelling behaviors with and without incorporated peptide were evaluated by atomic force microscopy (AFM) in Peak Force ${ }^{\circledR}$ Quantitative Nanomechanical Property Mapping (PFQNM) mode, while peptide loading and release was monitored by ellipsometry and confocal microscopy. 


\section{EXPERIMENTAL SECTION}

Materials. Poly-L-Lysine (pLys) of different molecular weights (pLys 1 kDa, pLys 10kDa, pLys $150 \mathrm{kDa}$ ) was obtained from Sigma-Aldrich (Schnelldorf, Germany), and used without further purification. Fluorescent Alexa Fluor-488 succinimidyl ester and Texas Red, mixed isomers, was from Invitrogen (Eugene, USA), while bisinchoninic acid (BCA) assay kit was from Pierce (Rockford, USA). All other chemicals used were of analytical grade and obtained from Sigma-Aldrich (Schnelldorf, Germany). Purified Milli-Q water was used throughout. Sodium acetate/acetic acid, Tris $\mathrm{HCl}$, and sodium carbonate/sodium bicarbonate buffers (10mM) were used for $\mathrm{pH} 4.0,7.4$, and 10.0, respectively.

Microgel synthesis. Poly(EA/MAA/BDDA) (ethyl acrylate/methacrylic acid/1,4-butandiol diacrylate) microgels were prepared using the seed-feed (starved feed) emulsion polymerization method previously reported by Rodriguez et al. ${ }^{21}$ The composition of the monomer emulsion feed was either 79/20/1, 66/33/1, or 39/60/1 (EA/MAA/BDDA) w/w, thus allowing both the degree of microgel swelling ('mesh size') and the electrostatic driving force for peptide adsorption to vary. Henceforth, microgels are abbreviated according to $\mathrm{w} / \mathrm{w}$ methacrylic acid content in the feed solution. Titration experiments showed these microgels to have a methacrylic content of $22.1 \pm 1.1,36.9 \pm 0.4$ and $63.3 \pm 1.5 \% \mathrm{w} / \mathrm{w}$, respectively (Table 1, Supplementary Material).

In the synthesis process, $31.5 \mathrm{~g}$ (of the total $260 \mathrm{~g}$ ) (EA/MAA/BDDA) monomer mixture was initially added to nitrogen-purged solution consisting of $1.8 \mathrm{~g}$ SDS in $517.5 \mathrm{~g} \mathrm{H}_{2} \mathrm{O}$ under stirring in a four-necked round bottom flask at $80^{\circ} \mathrm{C}$. This was immediately followed by addition of dipotassium hydrogen phosphate ( $3 \mathrm{~g}$ of a $7.7 \mathrm{wt} \%$ aqueous solution) and ammonium persulfate (APS, $3.6 \mathrm{~g}$ of $5 \mathrm{wt} \%$ ). After $30 \mathrm{~min}$, the remaining monomer mixture 
was added continuously $(2.6 \mathrm{ml} / \mathrm{min})$ over $90 \mathrm{~min}$. To achieve similar size range of the three microgel systems, a second initiator step (3.2 g of $3 \mathrm{wt} \%$ APS) was included in the case of MAA33 microgels, while two more additions were added (3.2 g of $5 \mathrm{wt} \%$ APS) in the case of MAA20. During the polymerization process, the size of the microgels was regularly sampled and measured with photon correlation spectroscopy using a BI-9000 Brookhaven light scattering apparatus (Brookhaven Instrument Cooperation, NY, USA), fitted with a $20 \mathrm{~mW}$ $\mathrm{HeNe}$ laser and the detector set at a $90^{\circ}$ scattering angle. When reaching the desired microgel size ( $\sim 100 \mathrm{~nm}$ diameter), the reaction was stopped by cooling, after which the microgel solution was extensively dialyzed against water.

Surface preparation. Silanization and microgel deposition. Silica substrates used were either glass coverslips, 0.16-0.19 mm thickness (Fisher Scientific, Göteborg, Sweden), or prepared from polished silicon wafers, oxidized to an oxide layer thickness of $30 \mathrm{~nm}$ (Semiconductor Wafer Inc., Hsinchu, Taiwan). The resulting silica substrates were cleaned, first in $25 \%$ $\mathrm{NH}_{4} \mathrm{OH}, 30 \% \mathrm{H}_{2} \mathrm{O}_{2}$ and $\mathrm{H}_{2} \mathrm{O}\left(1: 1: 5\right.$, w/w), and then again in $25 \% \mathrm{HCl}, 30 \% \mathrm{H}_{2} \mathrm{O}_{2}$ and $\mathrm{H}_{2} \mathrm{O}$ $(1: 1: 5, \mathrm{w} / \mathrm{w})$, both at $80^{\circ} \mathrm{C}$ for $5 \mathrm{~min}$, followed by extensive rinsing by water. Samples were then functionalized with 3-glycidoxypropyltrimethoxysilane (GOPS) to enable covalent immobilization of the microgels, using a protocol slightly modified from that previously reported by Wong et al. ${ }^{26}$. In short, microgel immobilization was obtained through reaction between carboxyl groups in the microgels and epoxy groups at the interface, the latter obtained by silane binding to surface silanol groups. This methodology is well established in literature for covalent reactions, both generally and for covalent reactions in surface modification.$^{27}$ For this purpose, the washed silica substrates were rinsed in $99.5 \%$ ethanol before being placed in dried glassware under $\mathrm{N}_{2}(\mathrm{~g})$. Dried toluene (400 ml), GOPS (100 ml), and Hunig's base $(3 \mathrm{ml})$ was then added under $\mathrm{N}_{2}(\mathrm{~g})$ and reaction refluxed with a condenser 
at $110^{\circ} \mathrm{C}$ for $24 \mathrm{~h}$. After reaction, samples were sonicated twice for $15 \mathrm{~min}$ in methanol, and then rinsed in dichloromethane and diethyl ether. The functionalized silica substrates were then immediately submerged in $0.1 \mathrm{w} / \mathrm{w}$ microgel solution, $\mathrm{pH} 5.1$, and incubated overnight at $50^{\circ} \mathrm{C}$. Unbound microgel were rinsed off and samples stored in water until further use. In order to allow detailed AFM analysis of the surface-bound microgels, including surfaceinduced deformation, microgels were grafted at sub-confluent densities (area fraction occupied about $10 \%$ ). The surface density can be straightforwardly increased, e.g., by increasing microgel concentration present during the grafting reaction, by increasing ionic strength, or by lowering $\mathrm{pH}$. Complete coverage can also be conveniently obtained by conventional spin-coating. None of these effects were, however, the focus of the present investigation. Instead, we have kept the microgel surface density constant at a level for which detailed AFM experiments could be performed, and effects of peptide size, microgel charge density, $\mathrm{pH}$, and ionic strength instead investigated.

Confocal laser scanning microscopy. Fluorescence labelling. pLys was labeled with Alexa488 according to standard protocol recommended by the supplier. In brief, $0.1 \mathrm{mg}$ of dye per $\mu$ mole of peptide was reacted for $2 \mathrm{~h}$ in $10 \mathrm{mM}$ Tris $\mathrm{HCl}$ buffer, $\mathrm{pH}$ 7.4. Unreacted dye was removed by size-exclusion chromatography using PD-10 columns (GE Healthcare, Uppsala, Sweden). The concentration of Alexa-488 was determined by absorbance measurements, using a Helios $\gamma 4.60$ spectrophotometer (Thermospectronic, Cambridge, UK), while peptide concentration was measured spectroscopically after complexation with bisinchoninic acid ${ }^{28}$, using a Saphire plate reader (Tecan, Männedorf, Switerland) at $562 \mathrm{~nm}$. Based on this, labeling densities were found to be between 0.01-0.1 fluorophore/peptide. Labeled and unlabeled polylysine was previously found to result in similar loading into, and de-swelling of, poly(acrylic acid)-based microgels. ${ }^{29}$ 
MAA33 microgels were fluorescently marked with Texas Red to demonstrate uniform microgel coverage obtained by this approach (Figure S2 a). In brief, $10 \mathrm{ml} 3.0 \mathrm{w} / \mathrm{w}$ MAA33microgels was diluted with carbonate buffer $(10 \mathrm{ml} ; 10 \mathrm{mM}, \mathrm{pH} 9)$ in a foil-covered roundbottom flask under stirring at $0{ }^{\circ} \mathrm{C}$. EDC $(1.9 \mathrm{mg}, 12.2 \mu \mathrm{mol})$ and Sulfo-NHS $(2.7 \mathrm{mg}, 12.7$ $\mu \mathrm{mol})$ was then added. After $20 \mathrm{~min}$ incubation, Texas Red $(0.32 \mathrm{mg}, 0.26 \mu \mathrm{mol})$ was added and the reaction left under stirring overnight. Unreacted fluorophore was separated using PD10 columns (GE Healthcare, Uppsala, Sweden). Immobilization of fluorescently marked microgels to silica substrate (at $0.1 \mathrm{w} / \mathrm{w}$ ) was done as described above. The covalent immobilization of the microgels is further illustrated by pronounced differences in pLys binding after microgel immobilization on bare and GOPS-treated coverslips (Figure S2 b).

Peptide binding and release. Immobilized microgels, obtained as described above, were equilibrated in fluorescently labeled peptide solution of various concentrations overnight in 10 $\mathrm{mM}$ Tris $\mathrm{HCl}$ buffer, $\mathrm{pH}$ 7.4. Fluorescence intensity of the peptide-loaded microgels was monitored with a Confocal Leica DM IRE2 laser scanning microscope (CLSM; Leica Microsystems, Wetzlar, Germany), equipped with an Ar laser, using $100 \times 1.40-0.70$ oil objective and Leica TCS SL software (Leica Microsystems, Wetzlar, Germany).

To investigate peptide release, microgels were preloaded, as described above, in $7.5 \mu \mathrm{M}$ peptide solution. Peptide desorption was then studied after transferring the peptide-loaded microgel coating to an excess of new buffer $(\mathrm{pH} 4.0,7.4$, or 10, all at $10 \mathrm{mM}$, or $\mathrm{pH} 7.4$ at either 1,10 , or $100 \mathrm{mM}$ Tris $\mathrm{HCl}$ ) during $2 \mathrm{~h}$ before measurement. (Both ionic strengths and buffer identity were chosen in order to allow straightforward analysis of electrostatic effects, rather than mimicking physiological conditions. Having said that, the difference between 100 
$\mathrm{mM}$ investigated and the $150 \mathrm{mM}$ physiological conditions is expected to be minor in these systems.) The intensity ratio thus obtained is expressed as $I / I_{0}$, where $I_{0}$ is the average intensity after overnight equilibration in peptide solution, and I the average intensity within the microgel layer after $2 \mathrm{~h}$ incubation in new buffer without peptide. Region of interest (ROI) analysis was performed on confocal images, comparing histogram mean intensity over $14.65 \times 14.65 \mu \mathrm{m}$ areas $(\mathrm{n} \geq 3)$, using the open access software ImageJ (National Institutes of Health, Bethesda, USA). Although complete release kinetics curves were not obtained, the procedure used here is well suited to clarify effects of peptide size, microgel charge density, $\mathrm{pH}$, and ionic strength on peptide release, for which major and systematic effects were observed. Importantly, the initial release (here monitored over a 2 hours) provided the most reliable data for such analysis due to higher fluorescence intensities and lower background contributions.

Ellipsometry. Peptide adsorption to MAA-microgels was also investigated by null ellipsometry, using an Optrel Multiskop (Optrel, Kleinmachnow, Germany) equipped with a $100 \mathrm{~mW}$ argon laser. All measurements were carried out at $532 \mathrm{~nm}$ with an angle of incidence of $67.52^{\circ}$ in a $5 \mathrm{ml}$ cuvette under stirring $(300 \mathrm{rpm})$. By monitoring the changes in state of polarization of light reflected by the substrate, the mean refractive index $(n)$ and layer thickness $(d)$ of the adsorbed layer can be obtained. With these parameters the adsorbed amount $(\Gamma)$ was calculated according to ${ }^{30}$

$$
\Gamma=\frac{\left(n-n_{0}\right)}{\mathrm{d} n / \mathrm{d} c} d
$$

where $\mathrm{d} n / \mathrm{d} c$ is the refractive index increment and $n_{0}$ is the refractive index of the bulk solution. The refractive index increment used was $0.154 \mathrm{~cm}^{3} / \mathrm{g}$. Corrections were routinely made for changes in the bulk refractive index caused by changes in temperature and excess electrolyte concentration. Prior to measurements, the substrate was allowed to stabilize in 10 
$\mathrm{mM}$ Tris $\mathrm{HCl}$ buffer, $\mathrm{pH}$ 7.4, for 30 min before peptide addition. Peptide was thereafter added to the desired concentrations, monitoring the adsorption for $1 \mathrm{~h}$, before proceeding to the next peptide concentration. In the experiments were MAA-content of the microgels was varied, peptide was directly added to a concentration of $7.5 \mu \mathrm{M}$ in the cuvette. All measurements were made in at least duplicate.

Atomic force microscopy. The effect of peptide uptake on microgel swelling and mechanical properties, in aqueous solution, was investigated by atomic force microscopy (AFM) (Dimension Fast Scan, Nanoscope V, Bruker ${ }^{\circledR}$, Santa Barbara, USA) in Peak Force ${ }^{\circledR}$ Quantitative Nanomechanical Property Mapping (PF-QNM) mode. This set-up enables simultaneous mapping of both topography and sample nanomechanical properties in liquid. ${ }^{31-}$ ${ }^{33}$ In the PeakForce ${ }^{\circledR}$ measurement, the scanner oscillates at a low frequency $(1-3 \mathrm{kHz})$, resulting in a tip-sample interaction with every cycle. The maximum force on the tip is predetermined and maintained by a feed-back loop during the scan, which provides the opportunity for non-destructive imaging. Each pixel in such an image represents the output parameters of a contact mechanical fit to the interaction of the tip with surface on approach and separation. From these graphs, obtained within each pixel of the image, mechanical properties such as modulus, deformation, and adhesion can be calculated and imaged, together with sample topography. ${ }^{31,32,34}$ Prior to measurement, samples were preloaded in $7.5 \mu \mathrm{M}$ peptide solution as described above. Silicon nitride cantilevers (ScanAsyst-Fluid ${ }^{+}$, Bruker ${ }^{\circledR}$, Santa Barbara, USA), with silicon tips of a nominal radius of $2 \mathrm{~nm}$ and spring constants ranged between 0.4 and $0.7 \mathrm{Nm}^{-1}$, were used throughout, calibrated according to a procedure described elsewhere. ${ }^{35}$ Images were collected with scan rates between 0.5 and $1.5 \mathrm{~Hz}$, maximum force of $800 \mathrm{pN}$, oscillation amplitudes between $50-110 \mathrm{~nm}$, scanner resonance frequency of $2 \mathrm{kHz}$, image resolution of 512 x 512 pixels, and scan sizes between $500 \times 500$ 
$\mathrm{nm}^{2}$ and $5 \times 5 \mathrm{~m}^{2}$. The larger scan areas were used to allow statistical analysis of topography images to increase the number of individual particles $(n \approx 150)$. Microgel volume was estimated as a spherical cap,

$$
V=\left(\frac{\pi h}{6}\right)\left(3\left(\frac{d}{2}\right)^{2}+h^{2}\right)
$$

where $V$ is particle volume, $h$ mean height, and $d$ mean diameter from topography images. NanoScope Analysis software V1.50 (Bruker, Santa Barbara, USA) was used for all AFM statistical particle analysis and image processing.

CryoTEM. Cryogenic Transmission Electron Microscopy (cryoTEM) investigations were performed with a Zeiss EM 902A Transmission Electron Microscope (Carl Zeiss NTS, Oberkochen, Germany), operating at $80 \mathrm{kV}$ and in zero loss bright-field mode. Digital images were recorded under low dose conditions with a BioVision Pro-SM Slow Scan CCD camera (Proscan GmbH, Scheuring, Germany) and analySIS software (Soft Imaging System GmbH, Münster, Germany). In order to visualize as many details as possible, an underfocus of 1-2 mm was used to enhance the image contrast. The method for sample preparation has been thoroughly described elsewhere. ${ }^{36}$ In short, samples were equilibrated at $25^{\circ} \mathrm{C}$ and at close to $100 \%$ atmospheric humidity within a climate chamber. A small drop $(\sim 20 \mu 1)$ of sample was deposited on a copper grid covered with a perforated polymer film and with thin evaporated carbon layers on both sides. Excess liquid was thereafter removed by blotting with a filter paper, leaving a thin film of the solution on the grid. Immediately after blotting, the sample was vitrified in liquid ethane, held just above its freezing point. Samples were kept below $165^{\circ} \mathrm{C}$ in a protected atmosphere during transfer and examination. 
Size measurements. Microgel size determination in the absence and presence of peptide was investigated by nanoparticle tracking analysis, using a NanoSight NS500 (NanoSight Ltd., Amesbury, UK), equipped with a $75 \mathrm{~mW}$ laser at $532 \mathrm{~nm}$, and the NTA 3.1 analytical software. Within an illumination device mounted under a microscope, particles passing through the beam path were visualized as small dots. From the displacements measured, diffusion coefficients of individual particles were obtained, the size of which was subsequently obtained from the Stokes-Einstein equation. The measurements performed at $23^{\circ} \mathrm{C}$, after overnight incubation of the samples at a microgel concentration of 108-109 particles per ml. Each size measurement was based on a $60 \mathrm{~s}$ video, analyzed using a screen gain of 2, camera level of 14, and a detection threshold of 5. Data are presented as the average and standard deviation of the $10 \times 3$ video recordings.

Zeta potential. The zeta potential of microgels in the absence and presence of peptide was determined by dynamic light scattering at a scattering angle of $90^{\circ}$, using a Zetasizer Nano ZSP (Malvern Instruments, Malvern, UK) and calculated according to the Smoluchowski model. Peptide/microgel mixtures were incubated overnight before measurements were initiated, in each case monitoring size over time to ensure absence of time-dependent effects. Measurements were performed in triplicate at $25^{\circ} \mathrm{C}$.

Microgel charge determination. In order to calculate the number of binding sites available within the microgels per surface unit area, the MAA content of the microgels was titrated using Mettler-Toledo Dl 15 titrator (Mettler Toledo, Columbus, USA) with a supporting electrolyte of $0.01 \mathrm{M} \mathrm{NaCl}$ present (Table 1, Supporting Material). Together with microgel concentration, determined using Nanoparticle tracking analysis (NTA; NanoSight NS500, 
Malvern, Amesbury, UK) and microgel dry mass, this provides the number of charged MAAgroups within the microgels at a given $\mathrm{pH}$, assuming individual group titration.

Statistics. Standard deviations, based on at least triplicate measurements, are provided throughout the paper. 


\section{RESULTS}

Effects of peptide molecular weight. The effect of peptide molecular weight on binding to surface-bound MAA33 microgels was investigated by CLSM. As shown in Figure 1a and most clearly seen for pLys $1 \mathrm{kDa}$, the peptides display concentration-dependent binding, tapering off above 10-15 $\mu \mathrm{M}$. Expressed in molar terms, peptide binding increased in the order $150 \mathrm{kDa}<10 \mathrm{kDa}<1 \mathrm{kDa}$, assuming the labeling density (0.01-0.1 Alexa per peptide) of the bound peptide molecules to be the same as that of non-adsorbed peptide. Supporting this, ellipsometry was used to obtain analogous data, but for non-labeled peptides (Figure 2). (Time-resolved ellipsometry shows peptide loading to be quite fast $(\approx 5 \mathrm{~min}$; Figure $\mathrm{S} 3)$.) Although there are some minor differences in terms of the relative binding of pLys $1 \mathrm{kDa}, 10$ $\mathrm{kDa}$, and $150 \mathrm{kDa}$ compared to the confocal microscopy data, the same binding order and similar binding ratios between the different molecular weight peptides was observed also with ellipsometry. Hence, fluorescence labeling only has minor effects on peptide binding in the presently investigated systems. 

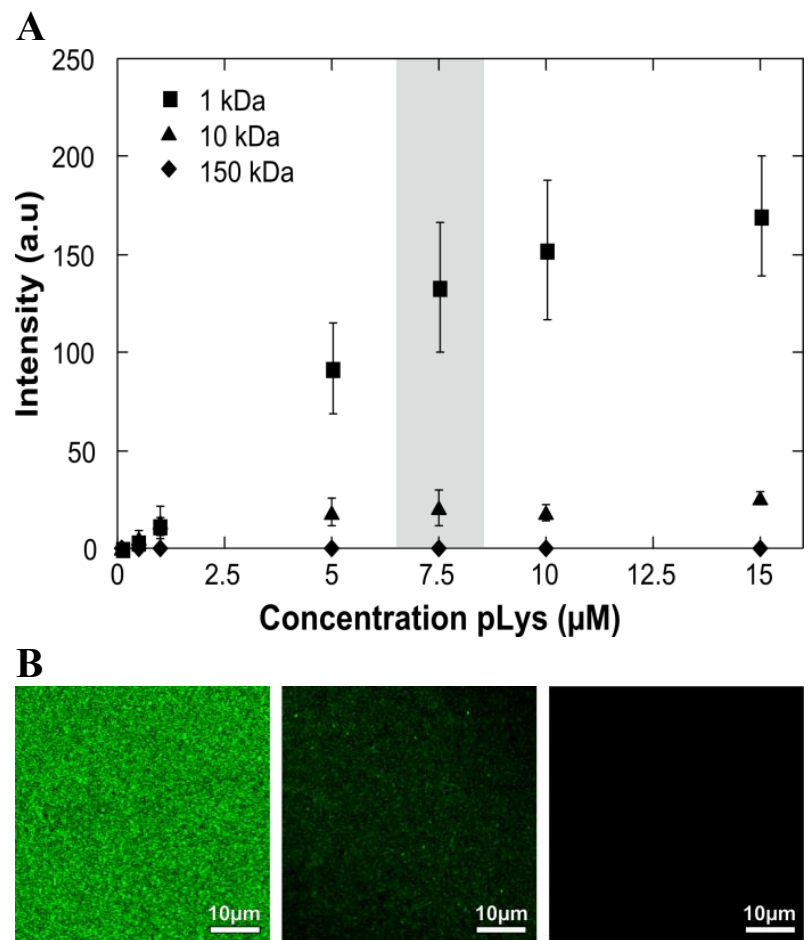

pLys $1 \mathrm{kDa}$

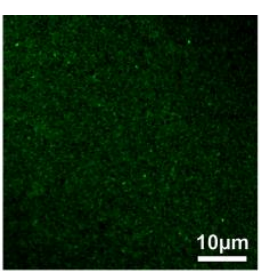

pLys $10 \mathrm{kDa}$

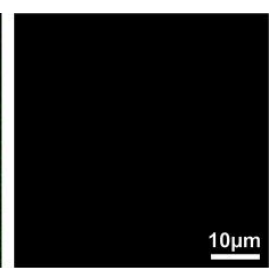

pLys $150 \mathrm{kDa}$

Figure 1. (A) Effect of peptide molecular weight on binding to surface-bound MAA33 microgels from $10 \mathrm{mM}$ Tris buffer, $\mathrm{pH}$ 7.4. (Average peptide intensities obtained over $14.65 \mathrm{x}$ 14.65 $\mu^{2}$.) (B) Representative CLSM images for the peptides investigated at a peptide concentration of $7.5 \mu \mathrm{M}$. 

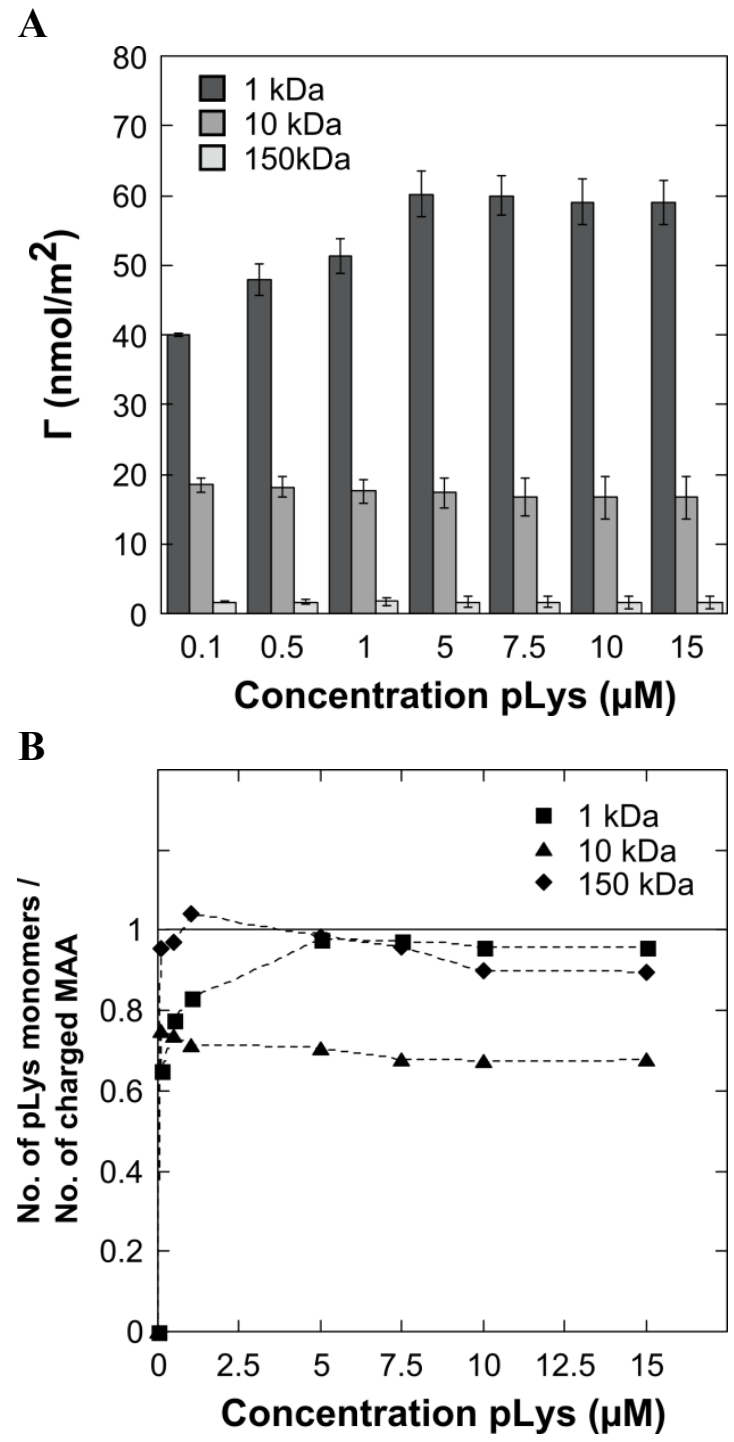

Figure 2. (A) Amounts of peptide adsorbed to MAA33 surface-bound microgels from 10 $\mathrm{mM}$ Tris buffer, $\mathrm{pH}$ 7.4, as measured with ellipsometry for pLys 1, 10, $150 \mathrm{kDa}$. (B) Number of pLys charges bound per acrylic acid group of the surface-bound microgels (i.e., charge ratio) upon peptide binding. 
In order to obtain information on the role of electrostatics, previously demonstrated to be key for the incorporation of cationic peptides into acrylic acid-based microgels ${ }^{10,12,29}$, the ellipsometry adsorption data was plotted also as the number of pLys charges bound per charged methacrylic acid group in the microgels (Figure 2b). Although estimated with an accumulated error over several techniques, and subject to uncertainties related to charge regulation, this simple analysis suggests that $\mathrm{pLys} 1 \mathrm{kDa}$ at a $5 \mu \mathrm{M}$ concentration and above fully neutralizes all available MAA-groups in the microgels. For pLys $10 \mathrm{kDa}$, less efficient microgel charge neutralization is observed, possibly related to reduced peptide distribution to the microgel core, in agreement with previously reported mesh size effects in poly(acrylicbased) microgels. ${ }^{12}$ From this perspective, the seemingly complete charge neutralization observed for pLys $150 \mathrm{kDa}$ is unexpected. Due to the large size of this peptide it is expected to distribute primarily to the microgel shells and being at least partly excluded from the microgel core. ${ }^{12}$ However, even if the $150 \mathrm{kDa}$ peptide chains undergoes some binding and distribution through the microgel network, a substantial part of the molecule may remain unbound, hence contributing to an artificially high degree of charge neutralization.

The presence of such an outer cationic shell for pLys $150 \mathrm{kDa}$ (and to a smaller extent pLys $10 \mathrm{kDa}$ ) is demonstrated by zeta potential measurements obtained using dispersed microgels (Figure 3a). The change of zeta potential to positive values in the presence of pLys $150 \mathrm{kDa}$ is striking and indicates surface localization of this peptide. Moreover, Figure $3 \mathrm{c}$ shows that protruding pLys induces bridging flocculation. Hence, for larger molecular weight peptides, quantification of charge neutralization is precluded by anchored but non-internalized peptides protruding from the microgel surface. Thus, while Figure $3 \mathrm{~b}$ shows that the ratio of peptide positive charges to microgel negative charges strongly influences the electrokinetic behavior of the peptide-loaded microgels, charge reversal occurs much earlier than a charge ratio of 
unity, demonstrating that pLys $150 \mathrm{kDa}$, and presumably to a smaller extent also pLys 10 $\mathrm{kDa}$, is preferentially located at the outer part of the microgels. 
A

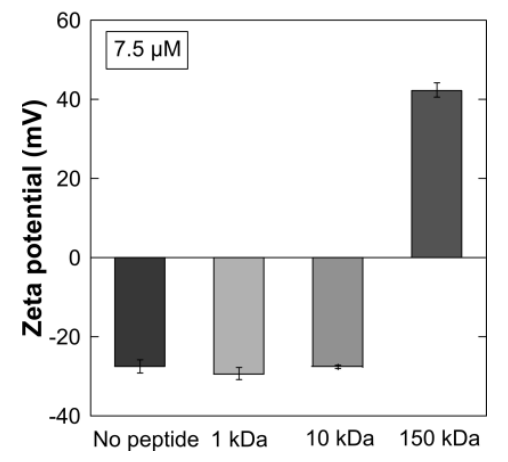

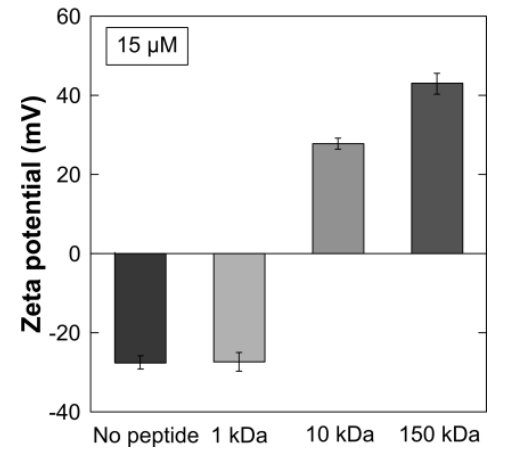

B

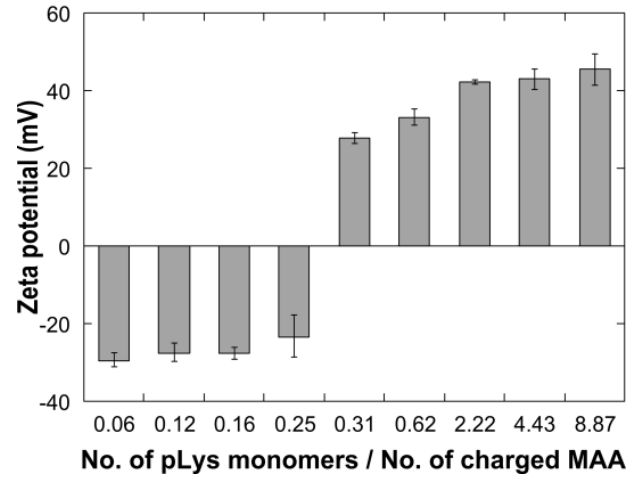

C

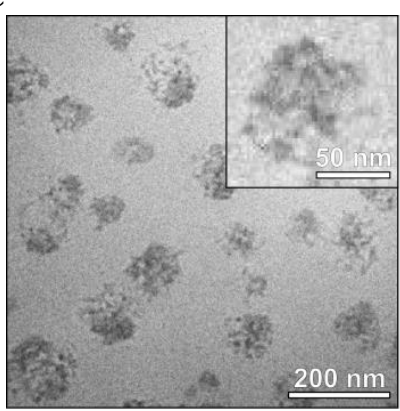

No peptide

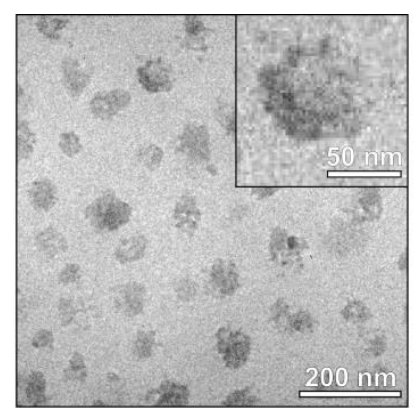

pLys $1 \mathrm{kDa}$

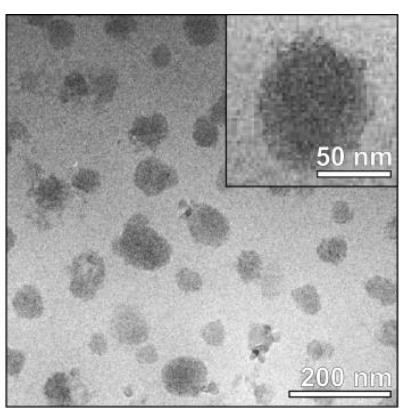

pLys $10 \mathrm{kDa}$

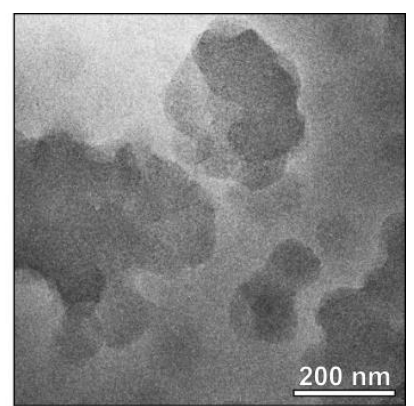

pLys $150 \mathrm{kDa}$

Figure 3. (A) Zeta potential of dispersed MAA33 $(0.01 \mathrm{w} / \mathrm{w})$ microgels in $10 \mathrm{mM}$ Tris buffer, $\mathrm{pH} 7.4$, with 7.5 (left) or 15 (right) $\mu \mathrm{M}$ pLys. (B) Zeta potential data plotted as a function of the ratio of peptide positive charges to microgel negative charges. (C) CryoTEM images of MAA33 $(0.1 \mathrm{w} / \mathrm{w})$ with and without incorporated pLys $1 \mathrm{kDa}, 10 \mathrm{kDa}$, and $150 \mathrm{kDa}$, at $7.5 \mu \mathrm{M}$ in $10 \mathrm{mM}$ Tris buffer, $\mathrm{pH}$ 7.4. Samples were incubated overnight prior to measurements. 
Effect of electrostatic interactions. In order to further clarify the importance of electrostatic interactions, effects of microgel charge density on peptide binding were investigated. As shown in Figure 4, both CLSM (Figure 4a and c) and ellipsometry (Figure 4b) demonstrate that an increased charge density, i.e., MAA content, in the surface-bound microgels results in an increased binding of cationic pLys. Together with the linear dependence of saturation adsorption versus microgel charge density, and an intercept close to zero (Figure S4), this confirms the dominance of electrostatic interactions in this system, in line with previously published work on similar systems. ${ }^{10,15,37,38}$ The agreement between CLSM and ellipsometry also shows that fluorescence labeling of the peptide does not markedly affect its microgel binding. 
A

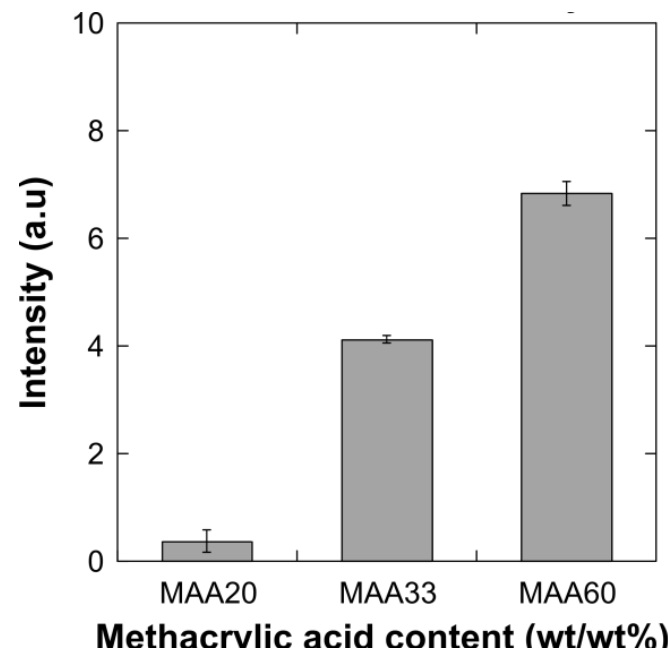

B

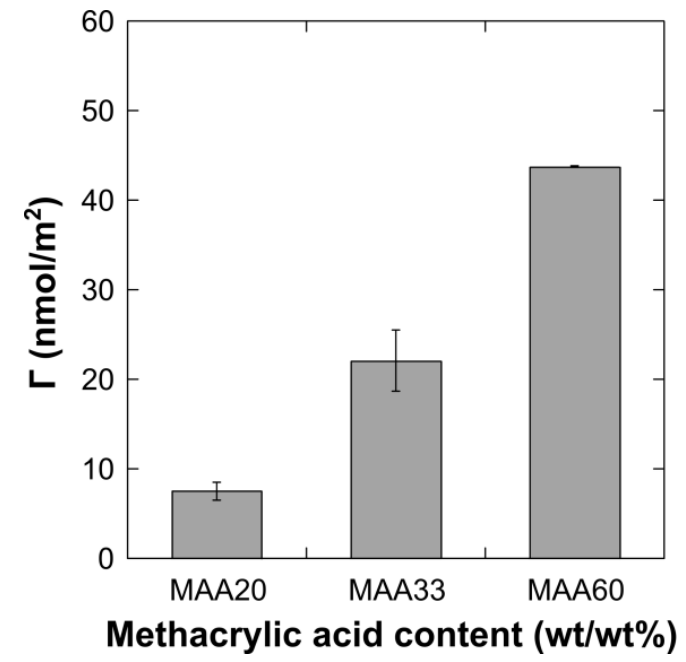

C
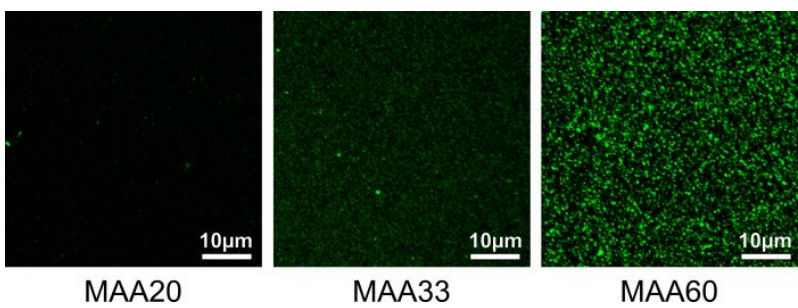

Figure 4. Effect of microgel charge density on peptide binding as obtained from CLSM (A) or ellipsometry (B). Measurements were performed for 20, 33, and $60 \mathrm{w} / \mathrm{w}$ MAA gels together with 7.5 $\mu \mathrm{M}$ pLys $10 \mathrm{kDa}$ in $10 \mathrm{mM}$ Tris buffer, $\mathrm{pH}$ 7.4. Shown also in $(\mathrm{C})$ are representative CLSM images from the experiments in (A). 
Next, peptide release, after uptake by the microgels, was induced by either ionic strength or $\mathrm{pH}$, and studied as a function of peptide molecular weight and microgel charge density. Figure 5 a,b shows that an increase in ionic strength, from 1 to $100 \mathrm{mM}$, only has relatively minor effects on peptide release at $\mathrm{pH} 7.4$, i.e., at maximum charge contrast between peptide and microgel, with electrolyte-induced desorption observed primarily for $1 \mathrm{kDa}$ pLys and the microgel of the lowest charge density. Peptide release is, however, quite dependent of the charge contrast between peptide and microgel, in this system conveniently tuned by varying $\mathrm{pH}$ (Fig. 5c,d). The $\mathrm{p} K_{a}$ of $\mathrm{pLys}$ has been reported to be around 9 (10.5 for isolated lysine monomers $^{12}$ ); whereas, the MAA-based microgel $\mathrm{p} K_{a}$ values were 6.4 - 7.0 (Table S1). Thus, at $\mathrm{pH} 4.0$, pLys is fully charged, but the MAA-based microgels almost uncharged, see Figure S1. At $\mathrm{pH} 10$, the reverse holds, i.e., the microgels are fully charged, but pLys only partially. ${ }^{12}$ At $\mathrm{pH} 7.4$, both microgels and peptide are close to fully charged, hence representing close to maximum charge contrast. As a result of this, binding is expected to be maximal at such intermediate $\mathrm{pH}$, and desorption rate suppressed. That this is indeed the case as shown in Figure 5, demonstrating limited desorption of all peptides at $\mathrm{pH} 7.4$, particularly so for pLys $10 \mathrm{kDa}$ and $150 \mathrm{kDa}$, but increased desorption of microgel-bound peptide at either $\mathrm{pH} 4.0$ or 10.0. The latter trend was observed for all peptides and all microgel charge densities. Quantitatively, desorption is facilitated particularly for the lowest molecular weight pLys 1 $\mathrm{kDa}$, whereas pLys $150 \mathrm{kDa}$ is most resilient to desorption. (The latter effect was confirmed also for non-labeled pLys $150 \mathrm{kDa}$ by zeta potential measurements - see Figure S5). Mirroring the increased adsorption with increasing microgel charge density discussed above, $\mathrm{pH}$-induced desorption decreased with increasing MAA content in the microgels, although quantitatively, the effects were relatively minor as a result of overall suppression of electrostatic interactions at $\mathrm{pH} 4.0$ and 10.0. 
A

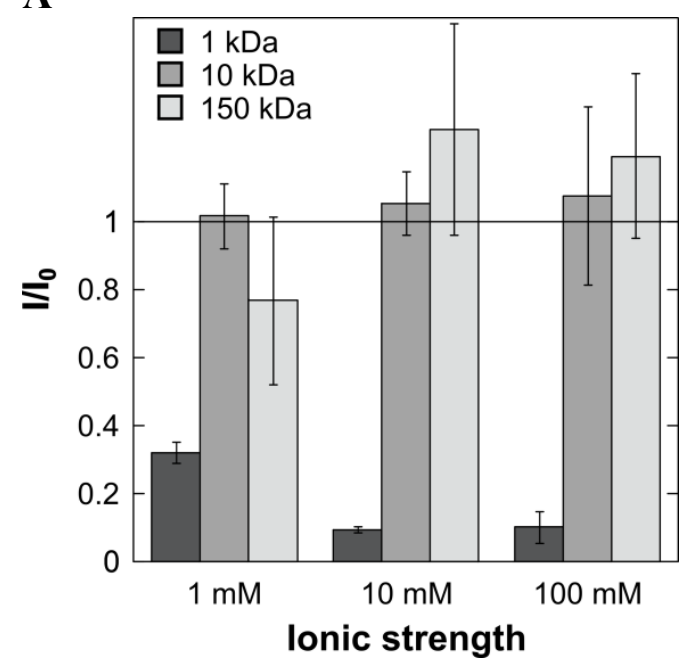

$\mathbf{C}$

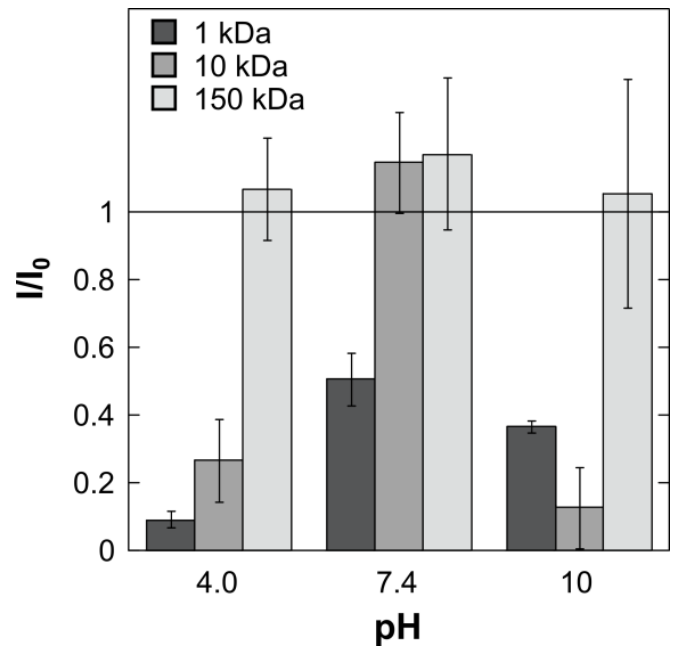

B

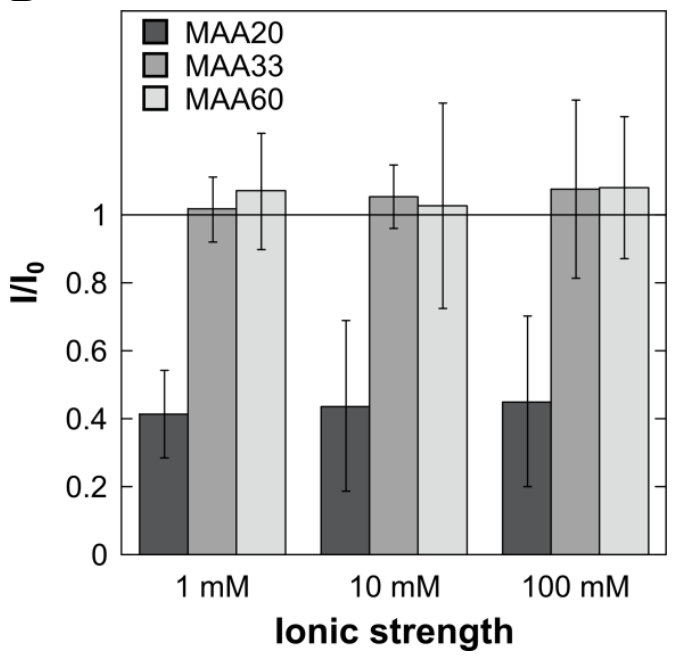

D

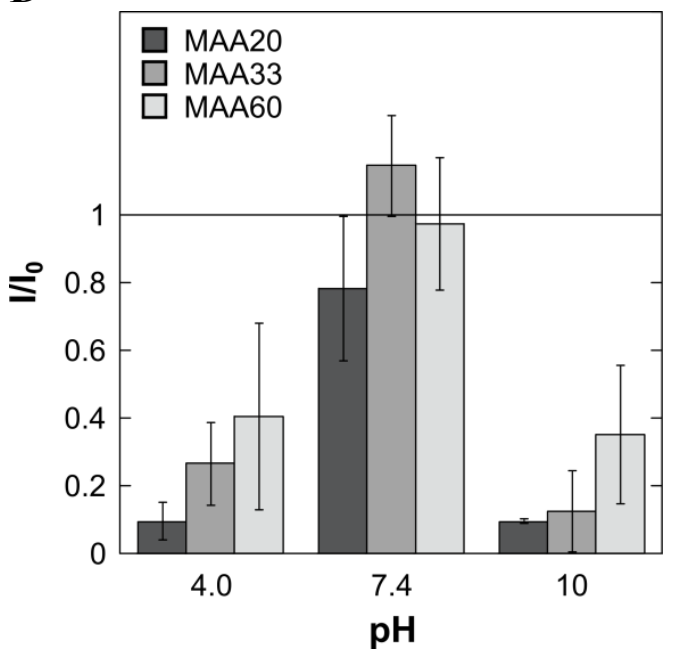

Figure 5. Release of microgel-bound pLys induced by either increasing ionic strength $(\mathrm{A}, \mathrm{B})$ or changing $\mathrm{pH}(\mathrm{C}, \mathrm{D})$. In $(\mathrm{A}, \mathrm{C})$, all measured were performed for surface-bound MAA33, loading the gels in $10 \mathrm{mM}$ Tris buffer, $\mathrm{pH}$ 7.4, and releasing at either the same $\mathrm{pH}$ and the indicated ionic strengths $(\mathrm{A})$ or at $10 \mathrm{mM}$ ionic strength and the indicated $\mathrm{pH}(\mathrm{C})$ ). For $(\mathrm{B}, \mathrm{D})$, experiments were performed for pLys $10 \mathrm{kDa}$, loading the gels in $10 \mathrm{mM}$ Tris buffer, $\mathrm{pH} 7.4$, and releasing at either the same $\mathrm{pH}$ and the indicated ionic strength (B) or at $10 \mathrm{mM}$ ionic strength and the indicated $\mathrm{pH}(\mathrm{D}))$. Results are expressed as $\mathrm{I} / \mathrm{I}_{0}$, where $\mathrm{I}_{0}$ is the fluorescence intensity after equilibration in $.5 \mu \mathrm{M}$ peptide solution but before initiation of desorption, while I is the fluorescence intensity after $2 \mathrm{~h}$ of incubation in, and release to, the respective buffer solution without peptide. 
Topographic and mechanical properties of peptide-loaded microgels. The mean volume of the individual microgel particles with and without peptide was extracted from Peak Force QNM topography images. Representative images and cross-section are shown in Figure 6a and $b$, respectively. To the best of our knowledge this is the first report of microgel crosssections of MAA-based, non-NIPAM containing microgels, and as shown for other surface adsorbed microgel systems the microgel shape upon binding is flattened. ${ }^{39-41}$

As shown in Figure $6 \mathrm{c}$ and $\mathrm{d}$, the volume of the surface-bound microgel decreases upon peptide uptake and the shape is further flattened. In agreement with the charge ratios obtained in Figure 2b, pLys $1 \mathrm{kDa}$ is most efficient in causing this deswelling, whereas the lower degree of charge neutralization for pLys $10 \mathrm{kDa}$ results in an analogously suppressed deswelling. For pLys $150 \mathrm{kDa}$, the lower peptide-induced deswelling further strengthens the notion of this peptide being primarily surface-bound, in agreement with reduced deswelling observed for (shell-forming) high-Mw pLys in poly(acrylic acid)-based microgels. ${ }^{12}$

As a result of peptide loading and subsequent microgel deswelling, the loaded gels become mechanically more rigid, as observed directly from a strongly reduced deformability (Figure 7). A striking feature of Figure 7 is that deformation depends little of peptide molecular weight, despite the differences between these in terms of peptide distribution. Notably, the shell-localized pLys $150 \mathrm{kDa}$ results in similar mechanical properties as the uniformly distributed pLys $1 \mathrm{kDa}$. 
A
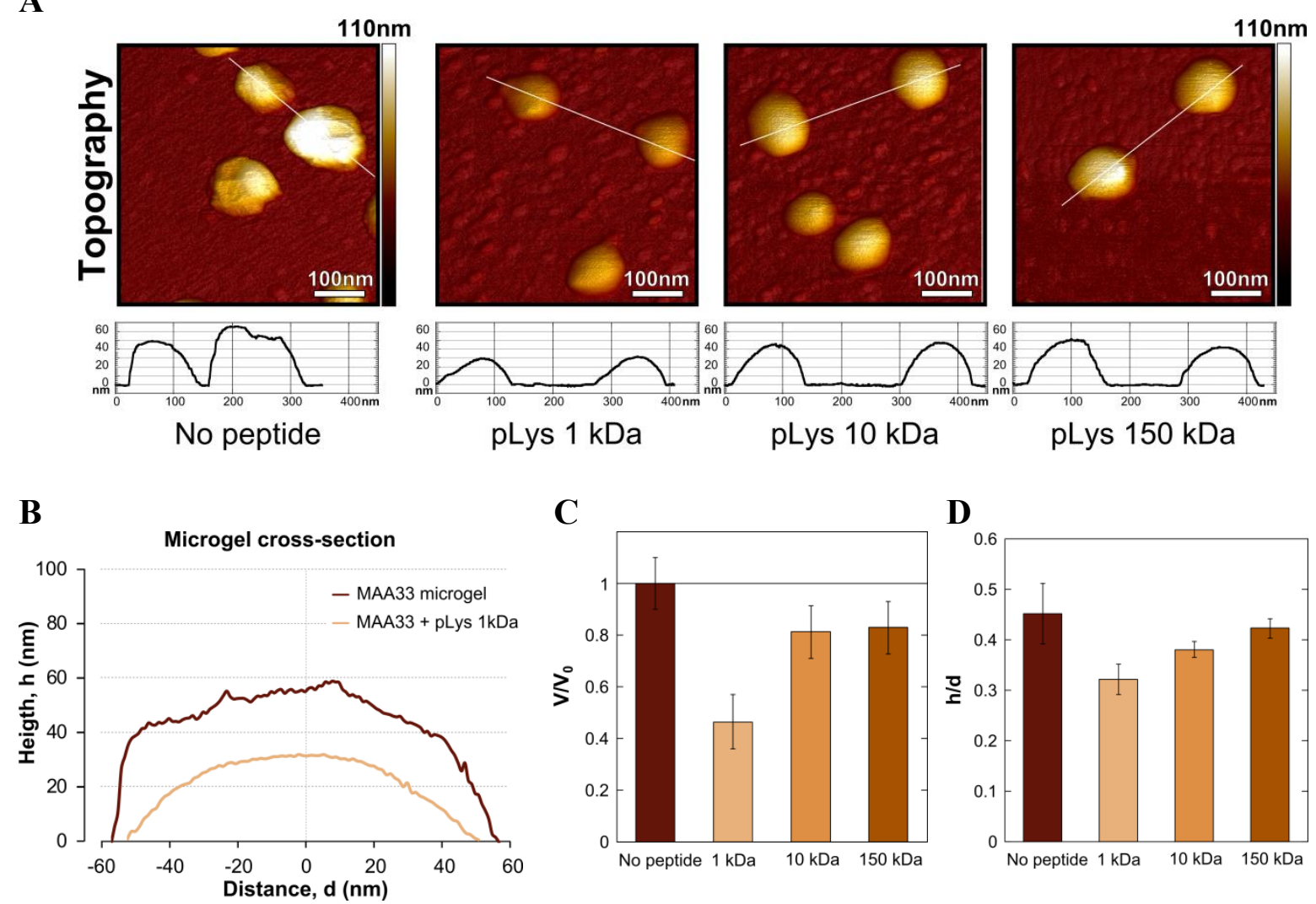

Figure 6. Representative 3D QNM images of microgel topography with corresponding crosssections. (A), as well as a representative close-up cross-section of a surface-bound microgel particle (B). (C) Effects of peptide binding on the size of surface-bound microgels. Results are expressed as $\mathrm{V} / \mathrm{V}_{0}$, where $\mathrm{V}$ and $\mathrm{V}_{\mathrm{o}}$ is the mean microgel volume in the absence and presence of pLys, respectively. (D) Quantification of asymmetric deswelling upon peptide loading, expressed as the ratio of $h$, height to $d$, diameter. All experiments were performed for MAA33 with $7.5 \mu \mathrm{M}$ of the indicated peptides in $10 \mathrm{mM}$ Tris buffer, $\mathrm{pH} 7.4$. 


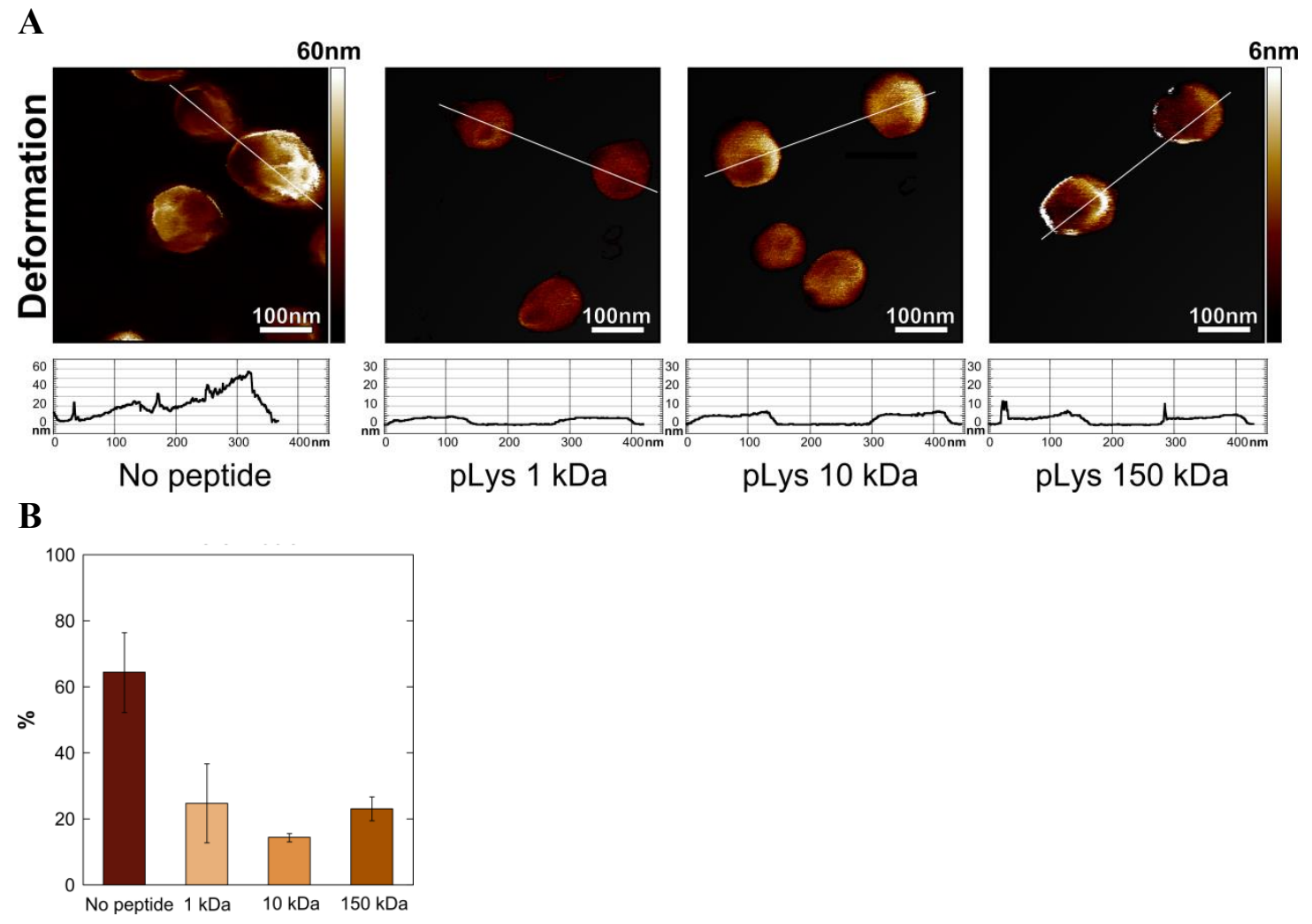

Figure 7. (A) Representative 3D images of microgel deformation obtained using PeakForce ${ }^{\circledR}$ Quantitative Nanomechanical Property Mapping with corresponding cross-section. (B) Microgel deformation after binding of $7.5 \mu \mathrm{M}$ pLys in $10 \mathrm{mM}$ Tris, $\mathrm{pH} 7.4$, to MAA33, represented as percentage of height deformation at an applied pressure of $800 \mathrm{pN}$. 


\section{DISCUSSION}

The present work aims at clarifying fundamental factors affecting peptide loading to, and release from, surface-bound and $\mathrm{pH}$-responsive microgels, with the ultimate aim to control the performance of such microgels as delivery systems for peptide and protein drugs. In particular, surface-bound microgels offer interesting opportunities as localized delivery systems of antimicrobial and anti-inflammatory peptides, since implant-associated infection and inflammation frequently involve multi-resistant strains and therefore require drugs able to combat these. ${ }^{42}$ In addition, fibrous capsule formation generally prevents systemic delivery in the treatment of biomaterials-associated infection and inflammation, hence a localized delivery systems is preferable. However, in order to enable such localized peptide delivery from microgel-coated biomaterials, factors determining peptide loading and release to/from such microgels need to be clarified.

A priori, it is not evident that surface-bound microgels behave similarly as dispersed ones in this context, since the presence of the underlying surface substantially changes mass transport to and from the microgels, since microgels are crowded at the interface and hence cannot be assumed to behave only as individual particles, since surface pinning may affect microgel swelling/deswelling transitions, and since the underlying surface may also interact with the peptide and thereby affect peptide-microgel interactions.

Addressing surface pinning and crowding effects in particular, there are an increasing number of studies of microgels either adsorbed or covalently immobilized at the solid/liquid interface in the absence of any load. In particular, attention has been directed to surface-bound temperature-responsive poly(N-isopropylacrylamide) (PNIMPAM) or (PNIPAM-co-acrylic acid) microgels. ${ }^{39,43-47}$ Results indicate that such surface-bound microgels retain their 
temperature-dependent volume transition. For purely charge-dependent microgels, less is known, although FitzGerald et al. investigated pH-dependent swelling of adsorbed poly(2vinylpyridine) microgels using in situ tapping mode AFM, and again found a swelling transition similar to that for the corresponding dispersed microgel system. ${ }^{48}$ Thus, although the presence of the surface generally affect microgel shape, notably causing microgel flattening to an extent depending on microgel $\mathrm{T}_{\mathrm{g}}$, cross-linking density, and microgel-surface interactions, ${ }^{44}$ volume transitions of surface-bound microgels seem not to be strongly affected by surface pinning or interfacial crowding effects, the latter at least at low to intermediate surface coverages.

Substantially less is known about the loading and release of drugs and other compounds to surface-loaded microgels. For example, FitzGerald et al. investigated pH-dependent swelling of adsorbed poly-[2-(diethylamino)ethyl methacrylate]- and poly[2-(diisopropylamino)ethyl methacrylate]-based particles, as well as their $\mathrm{pH}$-triggered capture and release of pyrene. ${ }^{49}$ Furthermore, Serpe et al. investigated thermally regulated uptake and release of doxorubicin from microgel films formed by layer-by-layer deposition of poly( $\mathrm{N}$-isopropylacrylamide-coacrylic acid) microgels and polycationic poly(allylamine hydrochloride) at 3aminopropyltrimethoxysilane-functionalized glass. ${ }^{7}$ However, as these films were thick, 10 30 microgel layers, they represent an intermediate between dispersed and surface-bound microgel monolayers. Using a related approach, Nolan et al. deposited similar microgel films, although somewhat thinner, in order to achieve thermally triggered insulin release. ${ }^{6}$ From direct pulsatile and extended release studies, the films were found to be able to release bursts of insulin over many cycles, the magnitude of the release controlled by the film thickness. Although the triggerability of the dispersed microgels thus remain also in surface-bound microgel films to the extent that it can be used for triggered release of both low-molecular 
weight compounds and peptides/proteins, no attempts were made in these studies to clarify effects of microgel and host compound properties for the functional performance of surfacebound microgels as localized delivery systems.

Given the relative sparsity of studies on peptide/protein-loaded surface-bound microgels, it is interesting to compare the present findings with those of Bysell et al., who investigated peptide loading into, distribution within, and release from poly(acrylic acid)-based microgels. ${ }^{10,12}$ In agreement with findings of the present investigation, pLys exclusion from the microgel network occurs for $150 \mathrm{kDa}$ pLys, resulting in pronounced shell formation. Furthermore, binding of both pLys and cationic lysine-based peptides to dispersed poly(acrylic acid) and poly(acrylic acid-co-acrylamide) microgels increased with microgel charge density, whereas peptide release increased with ionic strength (particularly for shorter peptides) and decreasing peptide-microgel charge contrast, achieved, e.g., by increasing or reducing $\mathrm{pH}$. Hence, for the presently investigated systems, in which surface crowding effects were reduced through keeping microgel surface densities below overlap conditions, and peptide-surface interactions were minimized, surface-bound microgels seem to behave qualitatively similarly to their dispersed counterparts.

Although there are thus similarities between dispersed and surface-bound microgels, the underlying surface does influence peptide-induced microgel deswelling in several ways. Notably, peptide binding reduced the negative surface potential of the microgels and resulted in first oligomerization and subsequently aggregation of dispersed, but not surface-bound, microgels (Fig. 3c). Although these effects mirror peptide binding qualitatively, correlation is less than quantitatively complete, possibly as a result of the simultaneous occurrence of bridging flocculation (pLys $150 \mathrm{kDa}$ ) and inhomogenous peptide binding. Furthermore, while 
zeta potential measurements conclusively demonstrate the formation of an outer peptide shell in the case of pLys $150 \mathrm{kDa}$ (Fig. 3a), and AFM demonstrated this to decrease peptideinduced deswelling for the surface-bound microgels (Fig. 6), pLys $150 \mathrm{kDa}$ was not completely excluded from the network of the corresponding dispersed microgel. Instead, pLys induced pronounced deswelling of the dispersed microgels (Figure S6), indicating that despite the shell formation also in the latter case (shown by the zeta potential measurements), this peptide was able to insert at least partially into the microgel network.

For the surface-bound microgels, on the other hand, peptide-induced deswelling was suppressed for pLys $150 \mathrm{kDa}$ as shown by the AFM data (Fig. 6), either due to the mesh size of these being affected by the underlying surface, or due to effect of the surface on the deswelling transition as such. Finally, the shell forming pLys $150 \mathrm{kDa}$ results in less flattening of the microgels than observed for the lower molecular weight peptides. A possible origin of this is the largely irreversible binding of the surface layer formed by the former peptide, demonstrated both by confocal microscopy and zeta potential measurements, which effectively results in a free energy penalty of deforming the loaded microgels. For pLys 1 $\mathrm{kDa}$, on the other hand, peptide adsorption is much more dynamic, and the loaded microgel can undergo flattening, favourable from a van der Waals interaction perspective, without paying the same surface tension penalty, through peptide re-organization within the microgel network.

Finally, we note that the importance of microgel flattening for microgel-based surface coatings containing peptide therapeutics in biomaterials- and drug delivery applications remains to be elucidated. However, given the pronounced flattening effects observed in the present investigation, as well as its consequences for mesh size distributions and the effects of 
mesh size for peptide diffusion within microgels ${ }^{29}$, flattening effects certainly cannot be dismissed at present and deserve to be further investigated. 


\section{CONCLUSIONS}

Cationic peptide binding to oppositely charged surface-bound microgels, as well as stimuliresponsive peptide release, is strongly dependent on electrostatic interactions. Thus, peptide loading is facilitated, and release suppressed, by increasing peptide net charge, increasing microgel charge density, reduced ionic strength, and at $\mathrm{pH}$ with maximal peptide-microgel charge contrast. Incorporation of peptide causes the microgels to deswell, and to become more rigid and less deformable. While short pLys distributes throughout the microgel network and results in quantitative charge neutralization, larger peptides are partially excluded from the microgel network. These opportunities to effectively tune peptide loading to, and release from, surface-bound microgels are qualitatively similar to those for dispersed microgels. However, the underlying surface affects peptide-induced microgel deswelling quantitatively, here demonstrated by effects of peptide molecular weight, with pLys $150 \mathrm{kDa}$ being able to induce much more pronounced de-swelling of dispersed microgels than of surface-bound ones. This illustrates the need for further investigations of effects of microgel and peptide properties for peptide loading and release, in order to enable rational design of surface-bound microgels as carriers of therapeutically more relevant cationic peptides, such as antimicrobial and anti-inflammatory peptides ${ }^{18}$ e.g., for combatting infection and inflammation in biomaterials-associated complications. 


\section{ASSOCIATED CONTENT}

Supporting Information. Table of microgel composition and key properties, microgel charge as a function of $\mathrm{pH}$ and CLSM control images of GOPS treatment, together with timeresolved ellipsometry, effect of microgel charge density on peptide binding along with peptide desorption kinetics and $\mathrm{pH}$-induced deswelling of dispersed microgels. This material is available free of charge via the Internet at http://pubs.acs.org.

\section{AUTHOR INFORMATION}

\section{Corresponding authors}

*E-mail: lina.nystrom@farmaci.uu.se; martin.malmsten@farmaci.uu.se.

\section{Present addresses}

$†$ Gelexir Healthcare Ltd, C/o - Ward Hadaway, The Observatory, Chapel Walks, UK

\section{Notes}

The authors declare no competing financial interest.

\section{ACKNOWLEDGEMENTS}

Jonny Eriksson is gratefully acknowledged for skillful technical support. This work was financed by the Swedish Research Council. 


\section{REFERENCES}

(1) Saunders, B. R.; Vincent, B., Adv. Colloid Interface Sci. 1999, 80, 1-25.

(2) Peppas, N. A.; Bures, P.; Leobandung, W.; Ichikawa, H., Eur. J. Pharm. Biopharm. 2000, 50, $27-$ 46.

(3) Bysell, H.; Mansson, R.; Hansson, P.; Malmsten, M., Adv Drug Deliv Rev 2011, 63, 1172-85.

(4) Sigolaeva, L. V.; Gladyr, S. Y.; Gelissen, A. P. H.; Mergel, O.; Pergushov, D. V.; Kurochkin, I. N.; Plamper, F. A.; Richtering, W., Biomacromolecules 2014, 15, 3735-3745.

(5) Wu, Y.; Wang, Q.; Libera, M., Macromolecular Symposia 2013, 329, 35-40.

(6) Nolan, C. M.; Serpe, M. J.; Lyon, L. A., Biomacromolecules 2004, 5, 1940-1946.

(7) Serpe, M. J.; Yarmey, K. A.; Nolan, C. M.; Lyon, L. A., Biomacromolecules 2005, 6, 408-413.

(8) Bridges, A. W.; Singh, N.; Burns, K. L.; Babensee, J. E.; Lyon, L. A.; Garcia, A. J., Biomaterials 2008, 29, 4605-4615.

(9) Bridges, A. W.; Whitmire, R. E.; Singh, N.; Templeman, K. L.; Babensee, J. E.; Lyon, L. A.; Garcia, A. J., J. Biomed. Mater. Res., Part A 2010, 94A, 252-258.

(10) Bysell, H.; Hansson, P.; Malmsten, M., J. Phys. Chem. B 2010, 114, 7207-15.

(11) Bromberg, L.; Temchenko, M.; Hatton, T. A., Langmuir 2002, 18, 4944-4952.

(12) Bysell, H.; Malmsten, M., Langmuir 2006, 22, 5476-5484.

(13) Mansson, R.; Bysell, H.; Hansson, P.; Schmidtchen, A.; Malmsten, M., Biomacromolecules 2011, 12, 419-424.

(14) Bysell, H.; Hansson, P.; Schmidtchen, A.; Malmsten, M., J. Phys. Chem. B 2010, 114, $1307-$ 1313.

(15) Månsson, R.; Frenning, G.; Malmsten, M., Biomacromolecules 2013, 14, 2317-2325.

(16) Widenbring, R.; Frenning, G.; Malmsten, M., Biomacromolecules 2014, 15, 3671-3678.

(17) Malmsten, M.; Bysell, H.; Hansson, P., Curr. Opin. Colloid Interface Sci. 2010, 15, 435-444.

(18) Schmidtchen, A.; Malmsten, M., J. Colloid Interface Sci. 2015, 449, 136-142.

(19) Pasupuleti, M.; Schmidtchen, A.; Malmsten, M., Crit Rev Biotechnol 2012, 32, 143-171.

(20) Gaspar, D.; Veiga, A. S.; Castanho, M. A. R. B., Front Microbiol 
2013, 4, 294.

(21) Rodriguez, B. E.; Wolfe, M. S.; Fryd, M., Macromolecules 1994, 27, 6642-6647.

(22) Lally, S.; Mackenzie, P.; LeMaitre, C. L.; Freemont, T. J.; Saunders, B. R., J. Colloid Interface Sci. 2007, 316, 367-375.

(23) Saunders, J. M.; Tong, T.; Le Maitre, C. L.; Freemont, T. J.; Saunders, B. R., Soft Matter 2007, $3,486-494$.

(24) Dalmont, H.; Pinprayoon, O.; Saunders, B. R., Langmuir 2008, 24, 2834-2840.

(25) Liu, R.; Milani, A. H.; Saunders, J. M.; Freemont, T. J.; Saunders, B. R., Soft Matter 2011, 7, 9297-9306.

(26) Wong, A. K.; Krull, U. J., Anal Bioanal Chem 2005, 383, 187-200.

(27) Blank, W.; He, Z. A.; Picci, M., J. Coat. Technol. 2002, 74, 33-41.

(28) Smith, P. K.; Krohn, R. I.; Hermanson, G. T.; Mallia, A. K.; Gartner, F. H.; Provenzano, M. D.;

Fujimoto, E. K.; Goeke, N. M.; Olson, B. J.; Klenk, D. C., Anal Biochem 1985, 150, 76-85.

(29) Bysell, H.; Hansson, P.; Malmsten, M., J. Colloid Interface Sci. 2008, 323, 60-69.

(30) De Feijter, J. A.; Benjamins, J.; Veer, F. A., Biopolymers 1978, 17, 1759-1772.

(31) Sweers, K.; van der Werf, K.; Bennink, M.; Subramaniam, V., Nanoscale Res Letter 2011, 6, 110.

(32) Sababi, M.; Kettle, J.; Rautkoski, H.; Claesson, P. M.; Thormann, E., ACS Appl. Mater. Interfaces 2012, 4, 5534-5541.

(33) Duner, G.; Thormann, E.; Dedinaite, A.; Claesson, P. M.; Matyjaszewski, K.; Tilton, R. D., Soft Matter 2012, 8, 8312-8320.

(34) Álvarez-Asencio, R.; Sababi, M.; Pan, J.; Ejnermark, S.; Ekman, L.; Rutland, M. W., Corros. Sci. 2014, 89, 236-241.

(35) Pyne, A.; Thompson, R.; Leung, C.; Roy, D.; Hoogenboom, B. W., Small 2014, 10, 3257-3261.

(36) Almgren, M.; Edwards, K.; Karlsson, G., Colloids Surf., A 2000, 174, 3-21.

(37) Smith, M. H.; Lyon, L. A., Macromolecules 2011, 44, 8154-8160.

(38) Yigit, C.; Welsch, N.; Ballauff, M.; Dzubiella, J., Langmuir 2012, 28, 14373-14385. 
(39) Höfl, S.; Zitzler, L.; Hellweg, T.; Herminghaus, S.; Mugele, F., Polymer 2007, 48, 245-254.

(40) Chen, M.; Cui, Z.; Edmondson, S.; Hodson, N.; Zhou, M.; Yan, J.; O'Brien, P.; Saunders, B. R., Soft Matter 2015, 11, 8322-32.

(41) Schroeder, R.; Rudov, A. A.; Lyon, L. A.; Richtering, W.; Pich, A.; Potemkin, I. I., Macromolecules 2015, 48, 5914-5927.

(42) Wang, Q.; Uzunoglu, E.; Wu, Y.; Libera, M., ACS Appl. Mater. Interfaces 2012, 4, 2498-2506.

(43) Horecha, M.; Senkovskyy, V.; Synytska, A.; Stamm, M.; Chervanyov, A. I.; Kiriy, A., Soft Matter 2010, 6, 5980-5992.

(44) Burmistrova, A.; Richter, M.; Uzum, C.; Klitzing, R., Colloid. Polym. Sci. 2011, 289, 613-624.

(45) Burmistrova, A.; von Klitzing, R., J. Mater. Chem. 2010, 20, 3502-3507.

(46) Wellert, S.; Hertle, Y.; Richter, M.; Medebach, M.; Magerl, D.; Wang, W.; Demé, B.; Radulescu, A.; Müller-Buschbaum, P.; Hellweg, T.; von Klitzing, R., Langmuir 2014, 30, 7168-7176.

(47) Burmistrova, A.; Richter, M.; Eisele, M.; Üzüm, C.; von Klitzing, R., Polymers 2011, 3, 1575 1590.

(48) FitzGerald, P. A.; Dupin, D.; Armes, S. P.; Wanless, E. J., Soft Matter 2007, 3, 580-586.

(49) FitzGerald, P. A.; Amalvy, J. I.; Armes, S. P.; Wanless, E. J., Langmuir 2008, 24, 10228-10234. 


\section{FOR TABLE OF CONTENTS USE ONLY}
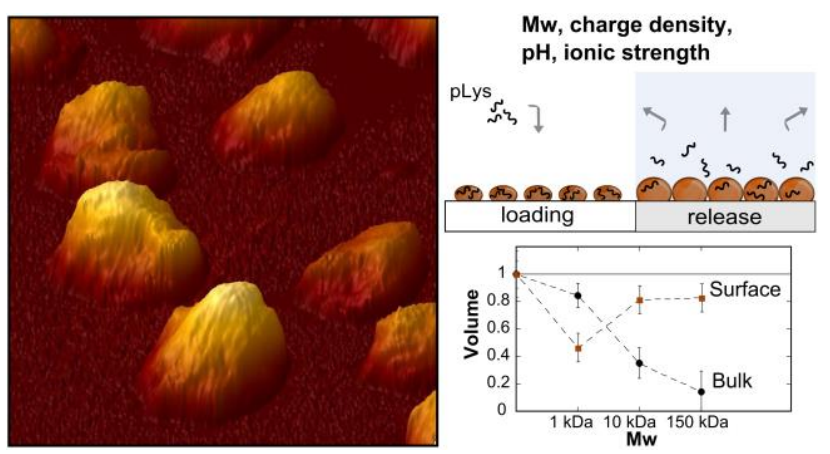

Title:

Factors Affecting Peptide Interactions with Surface-Bound Microgels

Authors:

Lina Nyström; Randi Nordström; Jane Bramhill; Brian R. Saunders; Rubén Álvarez-Asencio; Mark W. Rutland; Martin Malmsten 